REVISTA DE DERECHO UNED, NÚM. 18, 2016

\title{
EL CONCEPTO DEL DAÑO MORAL. ESTUDIOS DOCTRINALES
}

\author{
THE CONCEPT OF MORAL DAMAGE. \\ DOCTRINAL STUDIES
}

Blanca Casado Andrés

Resumen: En la actualidad se siguen produciendo debates sobre qué debe entenderse por daño moral, probablemente la abstracción del término sea la causa. No obstante, la autonomía del daño moral y su admisión por los tribunales resulta incuestionable, al igual que su resarcimiento. El estudio del tema se plantea desde un somero análisis de las dificultades con las que la doctrina se ha topado a la hora de definir el daño moral, y se concluye con el examen de algunas de las múltiples teorías y clasificaciones que se construyen en torno al difícil y complejo concepto del daño moral. Obviamente, el debate sigue abierto, y por lo tanto, el concepto del daño moral ha sido, es y seguirá siendo objeto de estudio, quizás porque a pesar de la imprecisión del término, en el fondo subyace el fantasma del resarcimiento o compensación de los denominados daños o perjuicios morales.

Abstract: At present debates continue taking place on what it must be understood by moral damage, probably the abstraction of the term is the reason. Nevertheless, the autonomy of the moral damage and his admission for the courts turns out to be unquestionable, as his indemnity. The study of the topic, it appears from a shallow analysis of the difficulties with which the doctrine has run up at the moment of defining the moral hurt, and concludes with the examination of some of the multiple theories and classifications that are constructed concerning the difficult and complex concept of the moral damage. Obviously, the debate remains opened, and therefore, the concept of the moral damage has been, is and it will continue being an object 
of study, probably because in spite of the imprecision of the term, in the bottom there sublies the ghost of the indemnity or compensation of the damages called or moral prejudices.

Palabras clave: daño moral, concepto, doctrina, clasificaciones.

Keywords: moral damage, concept, doctrine, classifications.

Recepción original: 18/02/2016

Aceptación original: 06/04/2016

Sumario: I. Las dificultades de conceptualización del daño moral. II. Las distintas concepciones doctrinales. II.A. El daño moral en contraposición o por exclusión del daño patrimonial: concepciones negativas. II.B. El daño moral en contraposición o por exclusión del daño patrimonial: concepciones positivas. III. Conclusiones. IV. Tabla de Jurisprudencia citada. V. Bibliografía.

\section{LAS DIFICULTADES DE CONCEPTUALIZACIÓN DEL DAÑO MORAL}

La determinación del concepto de daño moral es ardua y no exenta de controversias. No en vano se trata de uno de los problemas más complejos de toda la responsabilidad civil hasta el punto que en la actualidad, y a pesar de los años transcurridos desde que se inició su estudio, sigue siendo un tema en el que la doctrina no ha logrado ponerse de acuerdo ${ }^{1}$.

Para entender esta complejidad, es necesario remontarse al concepto general de daño en sentido jurídico ${ }^{2}$; no obstante, si problemática es la delimitación de su significado como noción general, las dificultades se acrecientan cuando tratamos de adentrarnos en la conceptualización del daño moral.

El daño constituye el eje del sistema de responsabilidad civil, y como tal, se nos presenta en el artículo 1.101 CC (responsabilidad contractual) y en el artículo 1902 CC (responsabilidad extracontractual) aunque ninguno de los preceptos señalados nos ofrece una noción esclarecedora de lo qué es el daño. A mayor abundamiento, el

${ }^{1}$ DOMíNGUEZ HIDALGO, C., El daño moral, T. I, Editorial Jurídica de Chile, Santiago, 2000, pág. 43.

${ }^{2}$ BUSTO LAGO, J. M., La antijuridicidad del daño resarcible en la responsabilidad civil extracontractual, Tecnos, Madrid, 1998, págs. 41-45, manifiesta que al Derecho no le interesa cualquier daño, solo toma en consideración el daño que integra un fenómeno jurídico, es decir, cuando pretende reparar o evitar el perjuicio que frustra expectativas aseguradas por el Derecho. 
tema se complica si tenemos en cuenta la diversidad de manifestaciones y matices que lo acompañan ya que impiden dar un concepto unitario del daño ${ }^{3}$.

El daño aparece como el elemento que conviene analizar primero en el estudio de la responsabilidad extracontractual puesto que es el que genera la obligación de indemnizar; sin daño no puede hablarse de reparación. Aparte, el concepto sirve para distinguir el ilícito civil -que precisamente se caracteriza por el daño- del ilícito penal, que a su vez se integra con la tipicidad ${ }^{4}$. Respecto a su contenido, aparece regulado en el artículo $1106 \mathrm{CC}^{5}$, por lo tanto, comprende: el damnum emergens o daño emergente (pérdida sufrida) y el lucrum cesans o lucro cesante (ganancia dejada de obtener). A su vez, de todas las clasificaciones posibles que se formulan sobre el daño, la más importante es la que tiene en cuenta la naturaleza del derecho subjetivo violado, es decir, del bien jurídico lesionado. Aunque existió una tesis muy arraigada y de antiguas raíces que consideraba el daño patrimonial como el daño por excelencia, en la actualidad esta teoría ha sido superada $^{6}$. En efecto, la doctrina ha reconocido universalmente la existencia de dos grandes categorías: daños patrimoniales y daños extrapatrimoniales. Esta distinción ha sido también acogida por las legislaciones de los países desarrollados ${ }^{7}$.

En definitiva, se trata de un concepto amplio, impreciso y esencialmente intuitivo, adjetivos que denotan la dificultad de ofrecer un concepto indisoluble de lo que significa el daño ${ }^{8}$, circunstancia que sin duda repercutirá y dificultará el establecimiento de una noción rotunda y precisa de daño moral.

${ }^{3}$ SANTOS BRIZ, J., La responsabilidad civil. Derecho sustantivo y derecho procesal, Montecorvo, Madrid, 1970, pág. 124; También, YZQUIERDO TOLSADA, M., Sistema de Responsabilidad civil, contractual y extracontractual, Dykinson, Madrid, 2001, pág. 144.

${ }^{4}$ YZQUIERDO TOLSADA, M., Sistema de..., op. cit., págs. 143 y ss.

${ }^{5} \mathrm{El}$ artículo $1106 \mathrm{CC}$ dispone: "La indemnización de daños y perjuicios comprende, no sólo el valor de la pérdida que hayan sufrido, sino también el de la ganancia que haya dejado de obtener el acreedor, salvas las disposiciones contenidas en los artículos siguientes».

${ }^{6}$ BUSTO LAGO, J. M., La antijuridicidad..., op. cit., pág. 79. Esta teoría identificaba el daño en sentido jurídico en relación con el patrimonio de la persona, con la noción de interés patrimonial y de bien económico así como, con la posibilidad de resarcirlo.

${ }^{7}$ Por todos, BREBBIA, R. H., El daño moral, Editorial Bibliográfica Argentina, Buenos Aires, 1950, pág. 67; Al respecto, también SALAZAR VALLEJO, C. Y GONZÁLEZ PUYANA, M. P., El daño moral, Pontificia Universidad Javeriana, Facultad de Ciencias Jurídicas y Socioeconómicas, Bogotá, 1990, págs. 10-11, apuntan que son numerosas las clasificaciones que sobre el daño existen pero ésta es quizás la única consensuada por la doctrina.

${ }^{8}$ BUSTO LAGO, J. M., La antijuridicidad..., op. cit., pág. 40. 
Son muchas las teorías conceptuales y clasificaciones del daño que circulan por los libros, aunque probablemente la más sencilla nos la ofreció el maestro DE CUPIS al poner de manifiesto que el daño no es nada más que el perjuicio, es decir, la aminoración o alteración de una situación favorable 9 .

Otra de las dificultades para llegar a la noción de daño moral, radica en la terminología que se utiliza en los distintos Derechos civiles para denominar esta figura jurídica ${ }^{10}$. Mientras que la doctrina francesa usaba la locución "dommage moral», la doctrina italiana tradujo esta expresión como "danno non patrimoniale», al tiempo que el Derecho civil alemán hablaba de "der nicht Vermögenssachaden ist» (daño inmaterial o extrapatrimonial en sentido amplio) ${ }^{11}$. El origen del problema comenzó en la interpretación latina que se realizó de la antigua institución germánica conocida como «wergeld» $\mathrm{o}$ "rescate de la sangre» o «dinero del dolor», más tarde conocida como «schmerzensgeld», reinterpretada a su vez por los autores del Código francés como «dommage moral». Esto dio lugar a que en los distintos países europeos se hablase de daños morales utilizando los términos que acabamos de nombrar y que no necesariamente significaban lo mismo, dando a su vez lugar a distintas indemnizaciones ${ }^{12}$.

El concepto «daño moral» no tiene un significado concreto y particular puesto que se integra de un conjunto muy heterogéneo de supuestos o hipótesis de daños, que además tienen la característica de irse renovando constantemente tanto a nivel jurisprudencial como dogmático ${ }^{13}$.

${ }^{9}$ DE CUPIS, A., Il danno. Teoria generale della responsabilitá civile. Dott. A. GiuffréEditore, Milano, 1946, págs. 5-7. Añade el autor clásico que hay que distinguir el daño como hecho jurídico, del daño entendido simplemente como fenómeno del orden físico. Literalmente en su célebre definición manifiesta: "La vita cuotidiana offre all'observatore anche il piú distratto lo spetaccolo di una serie molteplice e varia di danni. Danno null'altro significa che "nocumento o pregiudizio», vale a dire annientamento o alterazione di una condizione favorevole» (pág. 5); LLAMAS POMBO, E., Cumplimiento por equivalente y resarcimiento del daño al acreedor, Trivium, Madrid, 1999, pág. 143, manifiesta que "toda pérdida actual o futura, toda diferencia introducida en el patrimonio del acreedor (o de la víctima, si se trata de responsabilidad extracontractual), constituye daño, y debe ser indemnizada, con tal de que exista un nexo causal entre el daño producido y el hecho que obliga a indemnizar».

${ }^{10}$ Entiéndase como expresión jurídica y no en el sentido de traducción literal del término.

${ }^{11}$ Por todos, DE CUPIS, A., Il danno..., op. cit., pág. 32.

12 BARRIENTOS ZAMORANO, M., El resarcimiento por daño moral en España y Europa, Ratio Legis, Salamanca, 2007, págs. 37 y ss.

${ }^{13}$ BARRIENTOS ZAMORANO, M., «Del daño moral al daño extrapatrimonial: la superación del pretium doloris», Revista Chilena de Derecho, vol. 35, N. . 1, Editorial Pontificia Universidad Católica de Chile, Santiago, 2008, pág. 87. 
A mayor abundamiento, subyace otro problema de gran transcendencia y es el de la resarcibilidad. En efecto, el ordenamiento jurídico garantiza a la ciudadanía la posibilidad de indemnizar todos los daños patrimoniales producidos por culpa o negligencia de otro, sin embargo, no ocurre lo mismo cuando se trata de los daños morales. Solo sabremos si se resarcen los daños morales cuando conozcamos el concepto y viceversa; solo podemos conocer el concepto cuando se determine la forma en que el ordenamiento jurídico les otorga la debida protección, es decir, si todos los daños son indemnizables o solo algunos de ellos y bajo qué condiciones y qué características se indemnizan ${ }^{14}$. Precisamente, tanto las formas de reparación del daño como la determinación del quantum indemnizatorio, siguen estando sujetas, entre otros factores, a la interpretación del juzgador ${ }^{15}$, que con fundamento en el principio «iura novit curia» y la fase probática, tratará de dictar una sentencia justa y ecuánime, acorde con las circunstancias y particularidades que rodean el supuesto de hecho enjuiciable. Y todo ello, a pesar de los esfuerzos que en algunos casos ha realizado el legislador a fin de establecer determinados criterios para fijar la cuantía indemnizable y el modo más justo de reparar ${ }^{16}$. Al margen de los mismos, se tiende a confundir la existencia de daños extrapatrimoniales con la función que se otorga a la indemnización pecuniaria en concepto de daños morales ${ }^{17}$. Incluso, con cierta frecuencia el Tribunal Supremo ha utilizado la condena a indemnizar el daño moral para sancionar conductas reprensibles cuando su impacto patrimonial es bajo o difícilmente evaluable ${ }^{18}$, y aunque la finalidad

${ }^{14}$ DÍEZ-PICAZO, L., El escándalo del daño moral, Thomson-Cívitas, Pamplona, 2008, págs. 76 a 79; SANTOS BRIZ, J., La responsabilidad..., op. cit., pág. 139.

${ }^{15}$ RODRÍGUEZ MARÍN, C., "Introducción al Derecho de Daños (II)», en $M a$ nual de valoración del daño corporal. Guía de aplicación del sistema de baremación para accidentes de circulación, coord. LÓPEZ Y GARCÍA DE LA SERRANA, J., Thomson-Aranzadi, Navarra, 2007, págs. 67-68. Señala la autora que la reparación está en función de la naturaleza del daño (específico o pecuniario) y el quantum indemnizatorio se establecerá en función de lo solicitado y de la libre apreciación del Juez.

${ }^{16}$ Nos referimos al art. 9.3 de la LO 1/1982, de 5 de mayo, de Protección Civil del Derecho al Honor, a la Intimidad Personal y Familiar y a la Propia Imagen, que extiende la indemnización al daño moral para los ataques a estos derechos de la personalidad, atendiendo a las circunstancias del caso y a la gravedad de la lesión efectivamente producida, por lo que se tendrá en cuenta en su caso, la difusión o audiencia del medio a través del cual se ha producido así como, el beneficio obtenido por el causante de la lesión.

${ }^{17}$ MACÍAS CASTILLO, A., El daño causado por el ruido y otras inmisiones, La Ley, Madrid, 2004, pág. 400.

${ }^{18}$ GÓMEZ POMAR, F., «El sudor de la frente y el daño moral. Comentario a la STS, 1. a , 22.9.2004», InDret 1/2005, 2005, www.indret.com 
es loable habría que buscar otras fórmulas como endurecer las sanciones penales, dejando al margen la figura del daño moral ${ }^{19}$.

En general, nuestros tribunales no nos ofrecen una definición del daño moral. A pesar de que su admisión se remonta al año 1912, lo cierto es que la aportación jurisprudencial es meramente práctica; así y todo, no son pocas las resoluciones que analizan la cuestión de los daños morales pero la inmensa mayoría se limita a resolver el caso objeto de litigio, con una clara propensión a enumerar los supuestos más significativos en relación a los bienes protegidos y a ampliar el ámbito de esta clase de daños ${ }^{20}$. La interpretación jurisprudencial del concepto abarca desde la idea del «impacto o sufrimiento físico o espiritual que en algunas personas pueden producir ciertas conductas, actividades e incluso resultados ${ }^{21}$; hasta las diversas situaciones en las que tiene cabida la indemnización por este tipo de perjuicios: «impotencia, zozobra, ansiedad, angustia, trastorno de ansiedad, impacto emocional, etc.» (STS de 15 de junio de 201022), «sensación anímica de inquietud, pesadumbre, temor o presagio de incertidumbre» (STS de 22 de mayo de $\left.1995^{23}\right)$, «impacto emocional, incertidumbre consecuente» (STS de 31 de mayo de $2000^{24}$ ).

La cuestión de los daños morales ha sido últimamente debatida por el Grupo Europeo de Derecho de Daños con el propósito de fijar ciertas orientaciones para alcanzar una adecuada comprensión del daño no patrimonial o daño moral. Finalmente, este Grupo ha huido de las definiciones y ha evitado implantar un concepto unánime de lo que debemos entender por daño moral, lo que nos ratifica en la idea de la dificultad de conceptualización de este tipo de perjuicios ${ }^{25}$.

${ }^{19}$ ATIENZA NAVARRO, M. L., "Algunas cuestiones acerca de la responsabilidad civil por los daños al honor, a la intimidad y a la propia imagen», en Veinticinco años de aplicación de la Ley Orgánica 1/1982, de 5 de mayo, de protección civil del derecho al honor, a la intimidad personal y familiar y a la propia imagen, coord. por DE VERDA Y BEAMONTE, J. R., Thomson-Aranzadi, Navarra, 2007, pág. 303.

${ }^{20}$ CASADO ANDRÉS, B., «El concepto del daño moral bajo el prisma de la jurisprudencia», Revista Internacional de Doctrina y Jurisprudencia, Volumen 9, Universidad de Almería, Almería, 2015, págs. 1 y 23. Puede acceder a través de www.ual.es

${ }^{21}$ STS (sección 1. ${ }^{a}$ ) de 10 de julio de 2014 (RJ 2014\4318); Pte. Sr. D. José Antonio Seijas Quintana.

${ }^{22}$ STS (sección 1. ${ }^{\text {a) }}$ de 15 de junio de 2010 (RJ 2010\5151); Pte. Sr. D. Juan Antonio Xiol Ríos.

${ }^{23}$ STS (sección 1. a) de 22 de mayo de 1995 (RJ 1995\4089); Pte. Sr. D. Luis Martínez-Calcerrada y Gómez.

${ }^{24}$ STS (sección 1. ${ }^{\mathrm{a}}$ ) de 31 de mayo de 2000 (RJ 2000`5089); Pte. Sr. D. Jesús Corbal Fernández.

${ }^{25}$ En este sentido, el artículo 10:301 de Principios del Derecho Europeo de la Responsabilidad Civil, Viena, 2005, establece las bases para fijar la indemnización de los daños morales y aunque huye de fijar una definición expresa de lo que debe entender- 
No obstante, ha sido la doctrina más insigne la que ha estudiado con mayor profundidad la cuestión de los daños morales, partiendo de una serie de teorías que nos servirán de guía a la hora de saber qué es el daño moral, o cuando menos, nos hará reflexionar en el contenido de esta figura jurídica.

\section{LAS DISTINTAS CONCEPCIONES DOCTRINALES}

La falta de consenso entre la doctrina a la hora de definir el daño moral, ha tenido una consecuencia práctica que no es otra que la del surgimiento de numerosas teorías; entre otras muchas, destacaremos las más relevantes, centrándonos sólo en aquellas concepciones que distinguen el daño moral como un perjuicio autónomo en relación al daño material o patrimonial, y rechazando las que niegan esa independencia, puesto que la autonomía del daño moral es, según la doctrina más especializada, incuestionable ${ }^{26}$.

\section{II.A. El daño moral en contraposición o por exclusión del daño patrimonial: concepciones negativas}

Puede afirmarse que la mayoría de la doctrina acepta definir el daño moral en contraposición al daño patrimonial. Es la definición negativa o por exclusión, es decir, partiendo del concepto de daño patrimonial, cuyo contenido es más fácil de abarcar o comprender, se especifica ulteriormente el de daño moral ${ }^{27}$. De este modo, todo lo que no es susceptible de ser entendido como daño patrimonial o material se identifica con el daño moral, no patrimonial o extrapatrimonial, no

se por daños no patrimoniales en su lugar, establece algunos contenidos que integrarían el daño moral: sufrimiento, perjuicio a la salud física o psíquica, daño a la dignidad humana, a la libertad o a otros derechos de la personalidad, entre otros. El articulado puede consultarse a través de la página web: www.egtl.org.

${ }^{26}$ DOMÍNGUEZ HIDALGO, C., El daño..., op. cit., pág. 50. Argumenta la autora, que esta afirmación encontraba su apoyo positivizado a través del art. 125 de la anterior Ley 22/1987, de 11 de noviembre, de Propiedad Intelectual, al señalar que "en caso de daño moral procederá su indemnización, aún no probada la existencia de perjuicio económico». En la actualidad y con la derogación de aquella Ley, el vigente RD Legislativo 1/1996, de 12 de abril, por el que se aprueba el TRLPI también contempla en su art. 140.2.a., la indemnización por daño moral en idénticas condiciones probatorias.

${ }^{27}$ ROVIRA SUIERO, M. E., La responsabilidad civil derivada de los daños ocasionados al derecho, al honor, a la Intimidad Personal y Familiar y a la Propia Imagen, Cedecs, Barcelona, 1999, pág. 246. 
per se, sino por la dificultad para su valoración económica ${ }^{28}$. En realidad, estas concepciones del daño moral, no lo definen, sino que simplemente lo contraponen al perjuicio material o patrimonial.

No obstante, aún teniendo como denominador común la conceptualización del daño moral entendido en forma negativa, podemos distinguir tres pensamientos diversos: los que atienden al objeto del daño moral, los que parten de la falta de repercusión sobre el patrimonio, y los que entienden que el daño moral carece de equivalente en dinero ${ }^{29}$.

a) Concepción negativa que atiende al objeto del daño moral

Fiel exponente de esta teoría es DE CUPIS ${ }^{30}$ que para conceptualizar el concepto de daño moral sostuvo la idea de que el daño privado podía ser patrimonial o no patrimonial, dependiendo del objeto sobre el que recaiga. Entiende por daño no patrimonial (más comúnmente llamado moral): "aquél daño privado que no puede comprenderse en el daño patrimonial por tener por objeto un interés no patrimonial, o sea, que guarda relación a un bien no patrimonial». Sólo partiendo de la esencia misma de su objeto se puede entender el daño moral. La no comprensión en el daño patrimonial significa que el objeto del daño moral no contiene ninguna de las características que sirven para distinguirlo del daño patrimonial.

El profesor DE CUPIS señala que al distinguir el daño privado en patrimonial y no patrimonial, su esfera de actuación se divide en dos zonas que deben cubrir completamente todo el ámbito del daño privado, por lo tanto, los sufrimientos morales y las sensaciones dolorosas, no abarcarían todos los perjuicios que no son daños patrimoniales, ad exemplum, la disminución del prestigio y de la reputación pública constituyen un daño no patrimonial independientemente del dolor o amargura del sujeto que lo sufre. En consecuencia, sujetos pasivos del daño no patrimonial pueden ser también las personas jurídicas, por ejemplo, si sufren una campaña difamatoria o la violación de un secreto. Por consiguiente, si se quiere dar una noción lógi-

${ }^{28}$ MACÍAS CASTILlO, A., El daño causado..., op. cit., págs. 290-291.

${ }^{29}$ Lo apunta GARCÍA LÓPEZ, R., Responsabilidad civil por daño moral. Doctrina

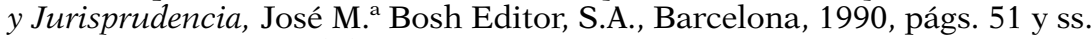

${ }^{30}$ DE CUPIS, A., Il danno..., op. cit., págs. 31-32. Señala el autor que el concepto de la no patrimonialidad no puede ser más que definido en contraposición al de la patrimonialidad. En la misma línea, ZANNONI, E. A., El daño en la responsabilidad civil, Astrea, 2. ${ }^{a}$ edic., Buenos Aires, 1987, págs. 287-288, entre otros muchos. 
ca y completa de daño no patrimonial, no deberíamos limitarnos al campo de los sufrimientos físicos o morales.

b) Concepción negativa que atiende a la falta de repercusión en el patrimonio

Para otros, sin abandonar el sendero de la teoría de la contraposición, lo relevante no es que el objeto sobre el que recae el daño producido sino la repercusión en el patrimonio. En este sentido, los hermanos MAZEAUD Y TUNC señalan que el daño moral es aquel perjuicio que no implica, para la víctima, ninguna consecuencia pecuniaria o disminución de su patrimonio. Es el perjuicio «extrapatrimonial», el «no económico». Tal fue la concepción que adoptó el Proyecto de Código franco-italiano de las obligaciones y contratos (1914-1928), que definió en su artículo 85 el daño moral como «el que no ataña en modo alguno al patrimonio y causa tan sólo un dolor moral a la víctima» ${ }^{31}$. Para los seguidores de esta doctrina, el daño moral es aquel que no produce detrimento patrimonial alguno.

Semejante criterio es el que propone MINOZZI que sostiene que puede existir un daño no patrimonial por lesión a un bien no patrimonial y viceversa. Si el daño repercute sobre el patrimonio será patrimonial y si cae fuera de la órbita de éste, extrapatrimonial o moral ${ }^{32}$.

${ }^{31}$ MAZEAUD, H., MAZEAUD, L., y TUNC, A., Tratado teórico y práctico de la responsabilidad civil delictual y contractual, T. 1, Vol. I, trad. de la 5. edic. por ALCALÁ ZAMORA Y CASTILLO, L., Ediciones Jurídicas Europa-América, Buenos Aires, 1961, pág. 424. Señalan que el perjuicio material es el perjuicio patrimonial mientras que el perjuicio moral es el perjuicio extrapatrimonial. Además, entienden, que a pesar de que el perjuicio no implique una pérdida de dinero para la víctima, "el daño moral posee necesariamente un valor, como el daño material, a los ojos de quienes admiten la reparación del mismo (...) que se traducirá en el abono de daños y perjuicios, en una suma de dinero", Ibidem, pág. 432.

${ }^{32}$ MINOZZI, A., Studio sul danno non patrimoniale (danno morale), 2. ${ }^{\text {a }}$ edic., Societá Edetrice Libraira, Milano, 1909, págs. 46 y ss. Este criterio, lo hace suyo DEMOGUE, R., Traité des obligations en gènèral. Sources del obligaciones, T. IV, Librairie Arthur Rousseau, Paris, 1924, pág. 45, para quien el verdadero daño moral es el aquel que no lesiona, ni aun afectando los derechos morales, el patrimonio de la persona. La conceptualización de estos autores ha sido muy criticada por otros insignes doctores, como BREBBIA, R. H., El daño..., loc. cit., pág. 88 y ss., que plantea, entre otras críticas, el supuesto en el que se lesiona el honor de una persona y en el que probablemente se produzcan consecuencias patrimoniales. De conformidad con la tesis de MINOZZI, llegaríamos al absurdo que el daño sería patrimonial, a pesar de que el honor es un derecho cuya característica más relevante es su extrapatrimonialidad. 
c) Concepción negativa que atiende a la imposibilidad de que el daño moral sea evaluado en dinero

Otras fórmulas, más modernas, nos las ofrecen los analistas económicos del Derecho de daños que también definen este tipo de perjuicios en contraposición con el daño patrimonial y en relación con la reparación, entendiendo que este tipo de daños no tienen equivalente en dinero. En efecto, entienden que mientras que el daño patrimonial provocaría una disminución de utilidad que es compensable con dinero o con bienes intercambiables por dinero; el daño no patrimonial o moral, por el contrario, implicaría una reducción del nivel de utilidad que ni el dinero, ni bienes intercambiables por éste, pueden llegar a compensar ${ }^{33}$.

\section{d) Criticas comunes a las teorías negativas}

Todas estas teorías negativas aunque tienen la virtud de reafirmar la autonomía del daño moral frente al perjuicio material tienen a su vez grandes detractores, entre ellos, destaca SCOGNAMIGLIO quien manifiesta que la definición negativa sólo puede admitirse cuando se trata de operar en la esfera de fenómenos homogéneos: como podría parecer porque se trata siempre de daño. Añade el autor que es pacífico aceptar, según se refleja en las directrices normativas, que los daños patrimoniales y los no patrimoniales, en especial los daños morales propiamente dichos, constituyen fenómenos diversos. En definitiva, considera superada la distinción entre daño patrimonial y no patrimonial, al entender que debería si acaso sustituirse por otra contraposición entre los daños jurídicamente relevantes (patrimoniales o personales) que como tales son resarcibles en todo caso; y los daños morales (solo en este sentido, no patrimoniales), que para el derecho italiano de la época solo eran resarcibles de manera excepcional. Para el citado autor, la noción de daño moral está en continúa y variada evolución, y su significado se corresponde con la terminología habitual: sufrimiento moral, dolor, etc. En todo caso, ese padecimiento psíquico debe ser siempre referido a un daño a la persona ${ }^{34}$.

${ }^{33}$ GÓMEZ POMAR, F., «Daño moral», InDret 1/2000, www.indret.com. Ejemplifica lo manifestado con el sufrimiento experimentado por el velocista que queda tetrapléjico como consecuencia de un accidente. El velocista ya no podrá disfrutar, con la misma intensidad, el dinero que no ha perdido.

${ }^{34}$ SCOGNAMIGLIO, R., "Il danno morale», Rivista di diritto civile, anno III, Parte Prima, Padova, Cedam, Casa Editrice dott. Antonio Milani, 1957, págs. 280 y 295 a 298. Al lado de esta opinión de SCOGNAMIGLIO se postula el profesor DÍEZ-PICAZO, L., El escándalo..., cit., pág. 76. 
Con diferente argumentación pero muy crítico también con los defensores de la teoría contraposición se nos muestra BREBBIA, quien se ha pronunciado abiertamente en contra de la definición negativa. Según el referido autor al mencionar sólo la condición de extrapatrimonialidad, se alude únicamente a una de las características de los daños morales y por ello, aunque en parte exacta, la definición resulta incompleta. Entiende que esta forma de definición solo puede ser aceptada si previamente se demuestra que los entes que se pretenden definir admiten únicamente dos clases de diversidad, de manera que no perteneciendo uno de los elementos que se pretende conceptualizar a un grupo, no pueda concluirse automáticamente que pertenece al otro. ${ }^{35}$

La tesis de la contraposición con el daño extrapatrimonial o teoría de la exclusión es el reflejo de las dificultades de conceptualización del daño moral, y el hecho de que sea aceptada por la mayoría de la doctrina representa una vía de escape para evitar los problemas que tanto la lógica como la exégesis del ordenamiento jurídico no pueden resolver ${ }^{36}$. Además, resulta bastante más fácil acudir al concepto claramente establecido del daño patrimonial, que no enfrentarse a la naturaleza del daño moral ${ }^{37}$.

\section{B. El daño moral en contraposición o por exclusión del daño patrimonial: concepciones positivas}

Con el fin de superar las críticas que subyacen a la conceptualización del daño moral en sentido negativo y, sobre todo, con la finalidad de ofrecer una definición más precisa del daño moral, nacieron este tipo de concepciones que, como las anteriores, comprenden un elenco diverso de formas de entender el daño moral.

${ }^{35}$ BREBBIA, R. H., El daño..., op. cit., pág. 86. El argumento de BREBBIA es discutible por dos motivos: en primer lugar, porque niega la autonomía de ambas clases de perjuicios, y en segundo lugar, y a pesar de que expresa que el tema de los derechos de la personalidad está íntimamente vinculado al de los derechos morales, olvida que el daño ocasionado a dichos derechos no empece la posibilidad de que se produzcan, asimismo, daños patrimoniales indirectos, que en su caso, deberán ser valorados. Es la reflexión de DOMÍNGUEZ HIDALGO, C., El daño..., op. cit., pág. 56; y de ROVIRA SUIERO (1999), La responsabilidad..., op. cit., págs. 249-252-253.

${ }^{36}$ DÍEZ-PICAZO, L., El escándalo..., locus cit., pág. 74.

${ }_{37}$ ÁLVAREZ VIGARAY, R., "La responsabilidad por daño moral», $A D C$, n. ${ }^{\circ} 19$, 1966, pág. 81. Señaló que: «es más fácil acudir al concepto claramente establecido de daño patrimonial que no enfrentarse con la naturaleza del daño moral e intentar la agrupación bajo un solo concepto de las diversas y variadas clases de daños que caen fuera del ámbito del daño patrimonial». 
a) El daño moral como «pretium doloris»

Es una de las conceptualizaciones más extendidas en la doctrina y también tenidas en cuenta por la jurisprudencia de nuestros tribunales ${ }^{38}$.

La noción que en la actualidad conocemos como daño moral tiene probablemente su origen en lo que el Derecho común llamó pretium doloris y que el Derecho germánico conoció como schmerzengeld ${ }^{39}$. Etimológicamente, la expresión pretium doloris se identifica con el precio del dolor, que a su vez se divide en dos especies: el puro dolor físico de la víctima y el perjuicio moral que afecta a la esfera psíquica de sus sentimientos y que se produce como consecuencia del perjuicio ocasionado ${ }^{40}$.

Entendido así, el daño moral se identifica como dolor, sufrimientos o padecimientos físicos o psíquicos injustamente ocasionados. Así, lo define SCOGNAMIGLIO, recalcando que no todos los dolores y padecimientos del ánimo que integran el reflejo subjetivo del daño constituyen daños morales, sino solamente aquellos que se producen en dependencia de un daño a la persona humana ${ }^{41}$.

En nuestro país, ha sido la línea doctrinal que ha continuado defendiendo, entre otros, ROVIRA, que se muestra cercana al criterio defendido por los italianos en cuanto considera que es la noción que mejor responde a la práctica del derecho ${ }^{42}$.

Sin embargo, el planteamiento del daño moral como «pretium doloris» no ha estado exento de críticas. Entienden, sus opositores que se trata de una forma demasiado estricta de entender el daño moral. En efecto, su restricción al dolor físico o psíquico de la persona, se olvida de la enorme heterogeneidad de daños extrapatrimoniales existentes en la actualidad, lo que impediría, por ejemplo, la indemnización de los daños morales cuando se lesionen derechos de la personalidad (honor, intimidad y propia imagen) tutelados expresa-

38 ÁLVAREZ VIGARAY, R., "La responsabilidad...», op. cit., pág. 83; ROVIRA SUIERO, M. E., La responsabilidad..., cit., pág. 248.

${ }^{39}$ SCOGNAMIGLIO, R., «Il danno...», op. cit., pág. 296; y siguiendo sus comentarios, el profesor Luis DÍEZ-PICAZO (2000), Derecho de daños, Civitas, Madrid, pág. 326.

${ }^{40}$ PÉREZ ONTIVEROS BAQUERO, C., Daño moral por incumplimiento de contrato, Thomson-Aranzadi, Navarra, 2006, pág. 112; VICENTE DOMINGO, E., Los daños corporales: tipología y valoración, José M. ${ }^{a}$ Bosh Editor, S. A., Barcelona, 1994, pág. 195. La autora prefiere utilizar los términos: daño físico y daño moral puro (entendido como afección de los sentimientos, de lo espiritual...).

${ }^{41}$ SCOGNAMIGLIO, R., «Il danno...», op. cit., pág. 296-297.

${ }^{42}$ ROVIRA SUIERO, M. E., La responsabilidad... cit., pág. 248. 
mente por nuestro derecho ${ }^{43}$. Otra de las dificultades con la que esta definición se encuentra, es que tendríamos que aplicar la misma ecuación tanto para los grandes sufrimientos, $v$. gr., las torturas, como para las nimias sensaciones de dolor ${ }^{44}$; en idéntico sentido, tampoco tiene en cuenta que lo que hoy consideremos de cierta entidad gravosa, mañana pueda parecer irrisorio; igualmente, olvida que para exista reparación de los sufrimientos o dolores es necesario que éstos se hayan probado, es decir, su simple existencia no da lugar a la indemnización resarcitoria ${ }^{45}$, ni tampoco tiene en cuenta que no solo se pueden causar daños morales a las personas físicas puesto que también las personas jurídicas pueden sufrir daños morales (pérdida del prestigio, buen nombre, etc. $)^{46}$. Por otra parte, y aunque esta forma de conceptualización del daño moral, teóricamente admite el resarcimiento de los de los daños no patrimoniales, en la práctica, niega dicha posibilidad, en cuanto que sostiene que solo deben ser indemnizados los perjuicios económicos derivados de los daños no patrimoniales (en sentido, de daños no patrimoniales indirectos). Si bien es cierto, admiten el resarcimiento indirecto del perjuicio no patrimonial, en realidad, lo priva de ser indemnizado con carácter autónomo e independiente ${ }^{47}$. A tenor de lo expuesto, ZANNONI argu-

${ }^{43}$ DOMÍNGUEZ HIDALGO, C., El daño..., cit., pág. 58-59, ÁlVAREZ VIGARAY, R., «La responsabilidad...», op. cit., págs. 84-85 al señalar que el concepto de daño moral no debe reducirse solo a los dolores o sufrimientos, también debe incluirse todo perjuicio no pecuniario que se derive de la lesión de un bien de la persona (salud, libertad, honor, etc.) o de sus sentimientos o afectos más importantes; siendo la nota fundamental que se trata de daños cuya naturaleza es no patrimonial.

${ }^{44}$ DÍEZ-PICAZO, L., El escándalo..., cit., págs. 84-85.

${ }^{45}$ BARRIENTOS ZAMORANO, M., "Del daño moral...», locus cit., págs. 89-90. En opinión de este autor, el daño moral se identifica con un concepto más amplio que el simple pretium doloris al que considera una especie más del daño moral, por lo tanto «no todo daño extrapatrimonial es pretium doloris aunque todo pretium doloris sí es un daño extrapatrimonial, hay una relación más bien de género a especie».

${ }^{46}$ RODRÍGUEZ GUITIAN, A. M., El derecho al honor de las personas jurídicas, Montecorvo, Madrid, 1996, págs. 108-109; similar pensamiento es el de SALVADOR CODERCH, P., El mercado de las ideas, Centro de Estudios Constitucionales, Madrid, 1990, págs. 387 y ss.; GARCÍA SERRANO, F. A., «El daño moral en la jurisprudencia civil», $A D C$, 1972, pág. 807. Señala el autor que el núcleo del daño moral no puede limitarse al «daño psíquico» o a la "perturbación del ánimo» porque sería como privar de protección a las personas jurídicas puesto que carecen de cuerpo físico. Con el fin de superar esta barrera, propone una distinción entre el daño físico a la persona y el daño moral, y define a este último como «el daño antijurídico, extrapatrimonial y no físico", a su vez, sugiere varios supuestos de daño moral, destacando el «ataque al honor» en cualquiera de sus facetas así como «el dolor y la angustia que derivan del atentado físico».

47 ÁLVAREZ VIGARAY, R., "La responsabilidad...» op. cit., págs. 83-84. VIGARAY lo explica mediante un ejemplo, el caso una lesión corporal. Según este planteamiento se procedería a indemnizar los gastos de curación y la falta de ganancia laboral, pero dejaría fuera lo más grave, la lesión corporal. 
menta que: «lo que define al daño moral no es, en sí, el dolor o los padecimientos», puesto que no se puede resarcir cualquier dolor o sufrimiento, sino solo aquel que es consecuencia de la privación de un bien jurídico sobre el cual el dolorido o el que sufre, tiene un interés jurídicamente reconocido ${ }^{48}$.

b) El concepto de daño moral basado en la clasificación de los daños

Algunos autores han centrado el estudio del perjuicio moral basándose en la división fundamental de los daños con arreglo a su naturaleza, así establecen que los daños pueden ser materiales y morales.

El daño material, señala JOSSERAND, puede alcanzar a la víctima tanto en su patrimonio como en su persona física; mientras que el daño moral puede afectar a la persona tanto en su honor, en su reputación o consideración (patrimonio moral) como en sus afectos (v. gr., la muerte inesperada de un familiar). Continúa manifestando, que existe consenso en considerar que el primero, el interés moral, estaría jurídicamente protegido pero dicha aquiescencia no parece tan clara a la hora de considerar la reparación del segundo, que por ser un simple interés de afecto, según entiende alguna parte de la doctrina, no debería tener equivalente pecuniario; afortunadamente, la jurisprudencia está asentada en sentido contrario ${ }^{49}$.

En términos parecidos se pronuncia CAMMAROTA, si bien es cierto que aunque parte de la misma premisa que acabamos de enunciar, es decir, entiende que los daños pueden ser materiales y morales, llega a conclusiones distintas. Para este autor argentino, el daño material resulta cuando se provoca un cuadro patrimonial alterado que la ley procurará reparar; mientras que el daño moral se produce cuando se provoca a una persona sufrimiento físico, molestias en su honor o seguridad, perturbación en sus afectos o daño en cualquier manifestación perniciosa intencionalmente provocada, y cuya repara-

${ }^{48}$ ZANNONI, E. A., El daño en..., op. cit., pág. 290. Es el caso, argumenta con un ejemplo, del automovilista que atropella a alguien. El conductor no está legitimado para solicitar una indemnización aunque por su susceptibilidad ante el padecimiento del atropellado, el accidente le haya causado una gran conmoción o sufrimiento en su esfera psíquica.

${ }^{49}$ JOSSERAND, L., Derecho civil, T. II, vol. I, revisado y completado por ANDRÉ BRUN, traducción de CUNCHILLOS Y MANTEROLA, S., Bosch y Cia, Buenos Aires, 1950, págs. 330-331. 
ción resulta indiscutible puesto que el perjuicio sufrido por una persona repercute directamente sobre su patrimonio ${ }^{50}$.

La diferencia fundamental entre el pensamiento de estos autores radica en la definición del daño material: mientras que para JOSSERAND el daño a las personas es daño material por ser algo corporal o visible (por ejemplo, la amputación de un brazo), para CAMMAROTA, la materialidad del daño se determina por la repercusión que éste produce en el patrimonio de la víctima (léase, la amputación del brazo del dibujante), es decir, el daño material no sería el corporal, sino el patrimonial que de éste se deriva ${ }^{51}$.

Dentro de este mismo planteamiento, hay autores que si bien exponen la antítesis tradicional entre el daño material y el moral, introducen una tercera categoría: el daño corporal (que comprende aspectos materiales y morales). Al respecto, uno de los máximos exponentes de esta teoría es CARBONNIER, quien conceptúa el daño material como aquel que se produce como consecuencia de los atentados contra los bienes o el patrimonio (daño patrimonial) y en el que caben dos aspectos: el damnum emergens (pérdida sufrida) y el lucrum cessans (ganancia frustrada) mientras que define el daño moral como aquel «que no produce detrimento patrimonial alguno». Señala que se produce daño moral cuando se lesiona «uno de los derechos extrapatrimoniales o primordiales (derecho al nombre, a la propia imagen, al honor y a la consideración) incluso añade que también puede haber daño moral "en la lesión de un derecho familiar (...) todavía más, a falta de un derecho definido, el daño reparable puede residir en el ataque a un interés moral o a los mismos sentimientos, siempre que éstos sean algo más que una simple susceptibilidad ${ }^{52}$.

Los detractores de esta teoría se plantean la inutilidad de esta clasificación tripartita de los daños, basan sus alegaciones en que no existe razón alguna para justificar la individualización del daño corporal como una tercera categoría de daños porque, en última instancia, o bien el daño es material (atendiendo a la materialidad) o bien el daño es moral (atendiendo a la extrapatrimonialidad). En definitiva, toda clasificación jurídica debe poseer características específicas que deriven en consecuencias jurídicas propias, por lo que carece de sen-

${ }^{50}$ CAMMAROTA, A., Responsabilidad extracontractual. Hechos y actos ilícitos, T. I, Editorial De Palma, Buenos Aires, 1947, págs. 77, 78, 93 y ss.

${ }^{51}$ GARCÍA LÓPEZ, R., Responsabilidad civil..., op. cit., pág. 58.

${ }^{52}$ CARBONNIER, J., Derecho Civil. Estudio Introductorio ("Droit civil»), T. II, Vol. III, trad. de la primera edic. francesa con adiciones de conversión al español por ZORRILLA RUIZ, M. M., Bosch, Barcelona, 1971, págs. 65-66. 
tido establecer una categoría como la de los daños corporales que está a caballo entre el daño moral y el daño material ${ }^{53}$.

En el mismo orden, la teoría que propone una concepción del daño moral basándose en la clasificación de los daños, es criticable porque "incluye lo definido en la definición». Por un lado, al situar los daños en el mismo plano obliga a buscar un concepto tan genérico del daño que resulta inane y por otro, no esclarece la cuestión de la resarcibilidad de los daños morales ${ }^{54}$.

c) El daño moral como menoscabo de los bienes y derechos de la personalidad o extrapatrimoniales

Con el fin de superar los defectos de las anteriores tesis, cuyo principal fallo era su vinculación con la persona natural en el caso del pretium doloris o la ineficacia, en el caso de la teoría basada en la clasificación de los daños, surge otra teoría que se centra en el carácter extrapatrimonial de los bienes y derechos lesionados.

Precisamente esta teoría entiende el daño estudiado haciendo referencia a la naturaleza jurídica del derecho subjetivo menoscabado por el hecho ilícito, calificada, a su vez, por la calidad patrimonial o extrapatrimonial (personal) del bien tutelado. Es la tesis también defendida por BREBBIA, que define el daño moral como «la especie, comprendida dentro del concepto genérico de daño, caracterizada por la violación de uno o varios de los derechos inherentes a la personalidad de un sujeto de Derecho» 55 .

Para esta corriente doctrinal, el daño moral se identifica con el atentado a derechos extrapatrimoniales y, por el contrario, el daño patrimonial, con la lesión de derechos de orden económico, bifurcándose a su vez en dos vertientes:

La primera vertiente, encuentra su máximo defensor en LALOU que sostiene la existencia de dos tipos de derechos: los derechos patrimoniales, que conducen a procurar a sus titulares satisfacciones pecuniarias (derechos reales, intelectuales, los que resulten del ejercicio

${ }^{53}$ GARCÍA LÓPEZ, R., Responsabilidad civil..., loc. cit., pág. 62.

${ }^{54}$ DÍEZ-PICAZO, L., El escándalo..., cit., págs. 78-79.

${ }^{55}$ BREBBIA, R. H., El daño... op. cit., págs. 69, 76, 83, 84. BREBBIA definió el daño como: "la violación de uno o varios de los derechos subjetivos que integran la personalidad jurídica de un sujeto producida por un hecho voluntario, que engendra a favor de la persona agraviada el derecho de obtener una reparación del sujeto a quien la norma imputa el referido hecho, calificado de ilícito». 
de la profesión, etc.) y los derechos extrapatrimoniales, entendidos en sentido amplio, que comprenden no solo todos los derechos de la personalidad (a la vida, a la libertad, al honor, al nombre, a la libertad de conciencia o de palabra) sino también los derechos políticos y los derechos de familia ${ }^{56}$.

En nuestro país, SANTOS BRIZ se ha mostrado cercano a esta forma de entender el daño moral, si bien reconoce que el daño moral afecta prioritariamente a los derechos de la personalidad, también afecta a otros derechos que no se incluyen dentro de los de la personalidad, tales como los derechos de familia, los corporativos, el estado de las personas jurídicas, etc ${ }^{57}$.

Otra segunda vertiente, más estricta, determina la extrapatrimonialidad de los daños cuando derivan de la lesión derechos de la persona. Esta corriente doctrinal aparece encabezada en nuestro Derecho, entre otros muchos, por DÍEZ-PICAZO y GULLÓN BALLESTEROS que definieron el daño moral como el que «comprende la lesión o violación de bienes y derechos de la persona. Son daños extrapatrimoniales, y se indemnizan prescindiendo de que un ataque a aquellos bienes y derechos tengan también repercusión en el patrimonio» ${ }^{58}$. La misma opinión sostiene, DE ÁNGEL que define los daños morales como «los infligidos a las creencias, los sentimientos, la dignidad, la estima social o la salud

${ }^{56}$ LALOU, H., Traité pratique de la responsabilicé civile, 5. ${ }^{\mathrm{a}}$ edic., Librairie Dalloz, Paris, 1955, pág. 105.

${ }^{57}$ SANTOS BRIZ, J., La responsabilidad..., op. cit., pág. 140. Apunta el autor, que el problema del concepto moral, se encuentra indisolublemente unido al de su reparación y aunque los derechos de la personalidad no se adecuan ni acomodan a una estimación pecuniaria, estos deben ser reparados, como así se ha aceptado de manera definitiva por la práctica jurídica (pág. 167).

${ }^{58}$ DÍEZ-PICAZO, L. y GULLÓN BALLESTEROS, A., Sistema de derecho civil,

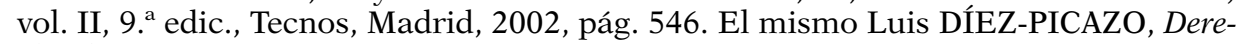
cho de ..., op. cit., págs. 328-329. En estas páginas, matiza la definición de daño moral al señalar que «debe reducirse al sufrimiento o perturbación de carácter psicofísico en el ámbito de la persona, sin proceder al respecto a concepciones extensivas, en las que la indemnización carece de justificación (...) poniendo énfasis en la idea de que no todo sufrimiento psicofísico engendra daño moral digno de indemnización, puesto que el resarcimiento solo tiene lugar cuando "aquél es consecuencia de derechos de la personalidad», por ejemplo, no lo sería si esas perturbaciones psicofísicas derivan de incumplimientos contractuales salvo que la prestación contractual del incumplidor afectara a derechos subjetivos del acreedor. El profesor DÍEZ-PICAZO, L., El escándalo..., loc. cit., págs. 83-84, ejemplifica el caso en la responsabilidad del abogado que no cumple las reglas de su profesión respecto al cliente que, por su mala praxis no accede a la tutela judicial efectiva. En estos casos, se debe rechazar la existencia de daño moral porque en realidad el letrado está violando una norma contractual, pero no lesionando un derecho fundamental que solo el Estado podría lesionar. Ésta es la llamada concepción estricta del daño moral que en cualquier caso, no tendría que ser presumido por los tribunales sino que debería ser objeto de algún tipo de prueba. 
física o psíquica; en suma, a los que se suelen denominar derechos de la personalidad o extrapatrimoniales» ${ }^{59}$ o LASARTE que apunta que ya desde el 6 de diciembre de 1912, fecha en la que el Tribunal Supremo reconoció la existencia de un daño moral, la lesión de los derechos de la personalidad se identifica con el concepto de daño moral ${ }^{60}$.

Otros, siguiendo esta estela, ponen su acento en el menoscabo a los bienes inmateriales o de la personalidad. Dentro de esta versión se halla DALMARTELLO, para quien daño moral es un complejo de todas las consecuencias dañosas que se pueden producir tanto sobre el ánimo como sobre la energía y sobre las condiciones familiares, sociales y mentales del perjudicado. Por lo tanto, si el daño en sentido genérico es la privación de un bien, añade el autor italiano, el daño moral es la privación de esos bienes que tienen un valor principal

${ }^{59}$ DE ÁNGEL YÁGÜE, R., Tratado de Responsabilidad Civil, Cívitas, Madrid, 1993, pág. 675; Partiendo del concepto al que se ha adherido la mayoría de la doctrina jurisprudencial más insigne, BARRIENTOS ZAMORANO, M., El resarcimiento..., op. cit., págs. 42-43, señala que el daño moral es: "la contravención de derechos extrapatrimoniales de una persona»; FERRER VICENTE, J. M., "La cuestión de los daños morales", Difusión Jurídica y Temas de Actualidad (cuadernos prácticos), Madrid, 2007, pág. 15. Daño moral comprende los ataques a los derechos de la personalidad así como las repercusiones en el ámbito psíquico afectivo; MARTÍNEZ CALCERRADA Y GOMÉZ, L., "El daño moral: sus manifestaciones en derecho español», Diario La Ley, n. ${ }^{\circ}$ 6996-7001, Madrid, 2008, ha definido los daños morales como «categorías anidadas en la esfera del intimismo de la persona, o intromisiones en sus derechos personalísimos, -honor, intimidad-y que, por ontología, no es posible emerjan al exterior, aunque sea factible que, habida cuenta la ocurrencia de los hechos (en definitiva, la conducta ilícita del autor responsable) se pueda captar la esencia de dicho daño moral»; ROCA Y TRÍAS, E., Derecho de daños. Textos y materiales, 5. a edic., Tirant lo Blanch, Valencia, 2007, pág. 185, que los define como «aquellos que afectan a la persona, en cualquiera de sus esferas que no sea la patrimonial»; RODRÍGUEZ MARÍN, C., "Introducción al...», cit., págs. 51 y 52. Señala la autora que «este tipo de daños, son los que recaen sobre bienes y derechos cuya naturaleza no es patrimonial...»; VICENTE DOMINGO, E., «El daño», en Tratado de responsabilidad civil, coordinado por REGLERO CAMPOS, L. F., V. I, 3. a edic., Thomson-Aranzadi, Navarra, 2006, pág. 273. Partidarios de un concepto que identifica el daño extrapatrimonial con el moral, entienden que los daños morales «son los que recaen en bienes o en derechos cuya naturaleza no es patrimonial y por la tanto carecen de la posibilidad de ser reparados en sentido estricto (...) Se trata de daños a bienes o derechos que no se pueden reponer porque no circulan en el tráfico jurídico, tales como el honor, el dolor, la integridad corporal, la tristeza, la muerte de un ser querido...».

${ }^{60}$ LASARTE ÁlVAREZ, C., Principios de derecho civil. Parte general y derecho de la persona, T. I, 6. ${ }^{\text {a }}$ edic., Trivium, Madrid, 1998, pág. 225. Resulta obligado señalar al respecto, que nuestra jurisprudencia no siempre ha aceptado la figura de responsabilidad civil por daño moral. Es más, podemos afirmar que la doctrina jurisprudencial ha sufrido varios cambios que se han delimitado en varias etapas: en una primera etapa, se negaba la posibilidad de obtener una indemnización por daño moral, solo a partir de 1912 se empiezan a indemnizar algunos supuestos, y es en la actualidad cuando se admite la posibilidad de indemnizar los daños morales en general, obviamente siempre y cuando se puedan probar. 
para la vida del hombre y que son: la paz, la tranquilidad del espíritu, la libertad individual, la integridad física, el honor, y otros afectos sagrados $^{61}$.

Pues bien, las críticas que se plantean a las posiciones doctrinales que conceptúan el daño moral como lesión a los bienes o derechos extrapatrimoniales, son también numerosas, a pesar de esta teoría es una de las más importantes en nuestro país, no solo a nivel teórico ${ }^{62}$ sino también práctico, al ser una de las concepciones más arraigadas entre nuestros tribunales. Comentan sus detractores, que se trata de una interpretación simplista de concebir el daño moral puesto que esta teoría parece sostener que cuando se lesionan bienes o derechos patrimoniales se estaría ante el daño material y cuando se lesionan bienes o derechos extrapatrimoniales, el daño sería moral. Los que critican esta forma de conceptuar el daño moral entienden que debe tenerse en cuenta que el interés que se pretende proteger puede ser tanto patrimonial como extrapatrimonial, v.gr., hay supuestos en los que se lesiona un derecho extrapatrimonial como la vida o la salud, y a la vez esa lesión provoca también un daño patrimonial como puede llegar a ser los gastos de curación. Ambos intereses pueden coexistir como presupuestos de un mismo derecho. Por lo tanto, el daño moral no se agota en el ataque a bienes o derechos extrapatrimoniales ${ }^{63}$.

DE ÁNGEL YÁGÜEZ, fiel postulante de esta teoría se defiende frente a las críticas argumentando que el rechazo de la misma obedece a los prejuicios que muchos juristas mantenían a la hora de admitir una valoración pecuniaria del daño moral: los bienes o derechos de la personalidad no eran dignos de ser traducidos a dinero. Argumenta DE ÁNGEL que hoy en día este recelo parece estar superado, y

${ }^{61}$ DALMARTELLO, A., «Danni morali contrattuali», $R D C$, anno XXV, Societá Editrice Libraria, Milano, 1993, pág. 55. Al respecto ha sido muy crítico, BREBBIA, R. H., El daño... op. cit., pág. 91, al señalar que el criterio que defiende DALMARTELLO tiene el inconveniente de llevar aparejada la imposibilidad de determinar cuáles son los bienes lesionados y que configuran los agravios morales, ejemplifica que todo atentado a la tranquilidad del espíritu sería, desde ese punto de vista, un daño moral, independientemente del tipo o intensidad que la turbación en la tranquilidad espiritual llevase consigo.

${ }^{62}$ LLAMAS POMBO, E., La responsabilidad civil del médico. Aspectos tradicionales $y$ modernos, Trivium, Madrid, 1988, pág. 234. Nuestra doctrina más reciente suele adherirse a esta forma de entender el daño moral, es decir, como el que afecta principalmente a los derechos de la personalidad, entendiendo que la producción de daños materiales no excluye a los morales y viceversa, puesto que ambos son compatibles, independientemente de que no se aprecien de forma individualizada por nuestros tribunales cuando concurren en el mismo supuesto.

${ }^{63}$ ZANNONI, E. A., El daño..., cit., págs. 288-289. En términos similares se manifiesta ROVIRA SUIERO, M. E., La responsabilidad..., cit., pág. 247. 
al contrario de lo que acontecía en tiempos precedentes, la indemnización del daño moral es una cuestión que no admite discusiones. En efecto, como señalan los críticos, la reparación del daño extrapatrimonial no excluye el hecho de que también se vean afectados intereses de carácter patrimonial, pero debe tenerse en cuenta que ambos daños están perfectamente delimitados, pese a que puedan ser objeto de una valoración unitaria ${ }^{64}$.

d) El concepto de daño moral basado en la naturaleza de los efectos o consecuencias que se derivan de la lesión

A fin de superar los defectos que pudiera tener la anterior concepción del daño moral basada en la naturaleza extrapatrimonial del derecho lesionado, surge otra teoría cuyo eje central para concebir el daño moral gira alrededor de la naturaleza de los perjuicios o daños que se derivan del hecho lesivo. Es DEMOGUE, uno de sus máximos representantes, quien se refiere a esta teoría como la del préjudice moral. Para saber si hay daño moral, dice DEMOGUE, no es necesario considerar el bien afectado, sino la naturaleza del perjuicio final. El verdadero daño moral es aquel que no lesiona, aún afectando a derechos morales, el patrimonio de la persona ${ }^{65}$.

A este planteamiento no le han faltado críticas. Señala BREBBIA que aceptar el criterio del autor francés, basado en la consideración de los efectos que se producen como consecuencia de la acción lesiva, supondría presuponer que los bienes personales o extrapatrimoniales como la vida, los sentimientos, el honor -que no tienen una traducción adecuada en dinero- no son susceptibles de tener un valor económico en cuanto inciden de una manera directa sobre la capacidad de producción del sujeto al que pertenecen ${ }^{66}$. Otros, como GARCÍA LÓPEZ,

${ }^{64}$ DE ÁNGEL YÁGÜEZ, R., Tratado de..., op. cit., pág. 675-676. Esta misma re-

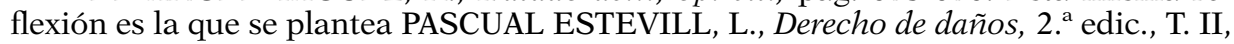
Bosch, Barcelona, 1995, págs. 872 y 891 . Subraya el autor que los perjuicios que lesionen bienes considerados «morales o extrapatrimoniales» aunque no se relacionen directamente con la esfera patrimonial del individuo, pueden causar además, por la vía indirecta, daños materiales, y en cualquier caso, el daño ha de ser indemnizado, reparado o compensado, pues es de justicia que el Derecho atienda a las lesiones producidas a los sentimientos, afectos, dignidad, honor, salud física, etc.

${ }^{65}$ DEMOGUE, R., Traité..., op. cit., pág. 45. Ilustra su planteamiento con un ejemplo, un daño que consista en destruir cartas familiares, tendrá la consideración de daño moral, a pesar de que los papeles no tengan valor económico.

${ }^{66}$ BREBBIA, R. H., El daño..., cit., págs. 88-89, explica este comentario acudiendo a un ejemplo: el honor es un bien personal que posee aparte de un valor moral o extrapatrimonial, un cierto valor económico puesto que un individuo desacreditado no 
plantean su crítica señalando que la esencia del perjuicio es el menoscabo, y no puede esperarse hasta las últimas consecuencias dañosas para hacer depender de la naturaleza de aquellas, las del daño. Cada situación lesiva comporta un daño independiente que no puede quedar abocado a la naturaleza del último daño ocasionado ${ }^{67}$.

Existe otro sector doctrinal próximo al planteamiento que también se refiere no al daño en su origen, sino en sus efectos. MESSINEO, por ejemplo, señala que el daño inmaterial es: «todo perjuicio originado directamente a la persona: el denominado daño moral puro (sin afectar, ni inmediatamente, ni tampoco mediatamente, el patrimonio de ella, o a la persona misma, en su capacidad productiva. A continuación, detalla algunos ejemplos de los que puede considerarse daño inmaterial: cuando se atenta a un derecho de personalidad moral o espiritual, cuando se lesionan los afectos, en el caso de desfiguración del rostro por cirugía estética, etc. ${ }^{68}$

El inconveniente que trae aparejado este tipo de conceptualización es, según GARCÍA LÓPEZ, que deja en manos del azar el que este tipo de perjuicios sean considerados verdaderos daños morales; puesto que dicha consideración dependería de que la eventualidad no hiciera generar de ellos consecuencias patrimoniales negativas ${ }^{69}$.

\section{CONCLUSIONES}

La dificultad de encontrar un concepto unívoco sobre el significado del daño moral es un tema arduo, de difícil solución. A pesar de que ante los tribunales no se cuestiona su admisión ni tampoco su

puede rendir económicamente lo mismo que si poseyera el respeto y la confianza de sus semejantes. Éste descrédito tendrá para el sujeto repercusiones morales y económicas, al influir indirectamente en su patrimonio.

${ }^{67}$ GARCÍA LÓPEZ, R., Responsabilidad civil..., loc. cit., pág. 70-71.

${ }^{68}$ MESSINEO, F., Derecho civil y comercial, traducción de SENTÍs MELENDO, S., T. VI (relaciones obligatorias singulares), Ediciones Jurídicas Europa-América, Buenos Aires, 1955, pág. 566.

${ }^{69}$ GARCÍA LÓPEZ, R., Responsabilidad civil..., loc. cit., pág. 74-75. Sin embargo, a pesar de estas críticas hacía esta teoría, merece la pena reseñar que GARCÍA LÓPEZ se ha planteado reinterpretar y conciliar la teoría basada en la clasificación de derechos (derechos extrapatrimoniales) y la basada en la naturaleza de sus efectos, de éste modo define el daño moral atendiendo tanto a la naturaleza de su objeto como a la consideración del daño como consecuencia perniciosa, como «el resultado perjudicial que tiene por objeto la lesión o menoscabo de alguno de los bienes o derechos correspondientes al ámbito estrictamente personal de la esfera jurídica del sujeto de derecho, que se resarcen por vía satisfactoria bajo el criterio equitativo del juez». 
resarcimiento, el problema de la conceptualización del daño moral sigue vigente.

El concepto del daño moral se fundamenta en los sentimientos, en el sufrimiento, en la reputación o en la angustia, en fin, afecta a la esfera psicofísica pero también supone el menoscabo de los bienes y derechos de la personalidad. De ahí que los mecanismos de reparación de esta clase de perjuicios resulten tan complejos. En efecto, ni el dinero ni ningún otro bien podrán compensar el daño que provoca la pérdida de un familiar en un accidente o el daño ocasionado a una empresa por la difamación de hechos falsos.

Volviendo al tema de concretización del concepto hay que destacar los esfuerzos realizados, tanto por parte de la doctrina como por parte de la jurisprudencia, por tratar de delimitar la noción del daño moral. No obstante, nos topamos con varios obstáculos:

1. ${ }^{\circ} \quad$ La amplitud del término. Así es, estamos ante una ingente cantidad de supuestos que no para de crecer; abarcan desde la pérdida de un familiar, los malos tratos, las depresiones o las interferencias en la salud hasta el menoscabo del honor o la reputación. Por tanto, no es posible establecer un «numerus clausus» que los delimite.

2. ${ }^{\circ} \quad$ La imprecisión o abstracción del término ya que es esencialmente intuitivo.

3. ${ }^{\circ}$ La dificultad probática de los daños morales. Naturalmente, no existe un baremo para medir el dolor o el sufrimiento. Un mismo hecho afecta a cada individuo de una manera diferente.

4. ${ }^{\circ} \quad$ El hecho de que también puedan verse afectados intereses de carácter patrimonial. No obstante, no se cuestiona el hecho de que ambos daños estén perfectamente delimitados, pese a que puedan ser objeto de una valoración unitaria.

5. ${ }^{\circ}$ El establecimiento de un sistema compensatorio justo y equitativo.

6. ${ }^{\circ}$ La subjetividad que impregna el propio concepto y que deja en manos de los juzgadores la determinación del quantum indemnizatorio.

Todos estos problemas han contribuido a que en la práctica, salvo excepciones, los daños o perjuicios morales se releguen a un segundo plano. No obstante, no se cuestionan pese a que conceptualizarlos resulte una peliaguda tarea que muchos se han afanado en desenmarañar con poca fortuna. En palabras del profesor DÍEZ PICAZO ${ }^{70}:$ «no es lo más grave la trivialización que se produce de este enormemente difícil concepto, sino la deformación que es consecuencia de ello, de

${ }^{70}$ DÍEZ-PICAZO, L., El escándalo..., op. cit., pág. 13. 
manera que si era comprensible que nunca hubiéramos tenido una idea especialmente clara de qué debe entenderse por "daño moral», esa idea es hoy menos clara que nunca».

\section{TABLA DE JURISPRUDENCIA CITADA}

\begin{tabular}{ccl}
\hline Tribunal, sala y fecha & Referencia & \multicolumn{1}{c}{ Magistrado-Ponente } \\
\hline STS, $1 .^{\text {a }}, 22.5 .1995$ & RJ 1995\4089 & Luis Martínez Calcerrada y Gómez \\
\hline STS, $1 .^{\text {a }}, 31.5 .2000$ & RJ 2000\5089 & Jesús Corbal Fernández \\
\hline STS, $1 .^{\text {a }}, 22.9 .2004$ & RJ 2004\5681 & Luis Martínez-Calcerrada y Gómez \\
\hline STS, $1 .^{\text {a }}, 15.6 .2010$ & RJ 2010\5151 & Juan Antonio Xiol Ríos \\
\hline STS, $1 .^{\text {a }}, 10.7 .2014$ & RJ 2014\4318 & José Antonio Seijas Quintana \\
\hline
\end{tabular}

\section{BIBLIOGRAFÍA}

ÁLVAREZ VIGARAY, R., «La responsabilidad por daño moral», $A D C$, 1996.

ATIENZA NAVARRO, M. L., «Algunas cuestiones acerca de la responsabilidad civil por los daños al honor, a la intimidad y a la propia imagen", en Veinticinco años de aplicación de la Ley Orgánica 1/1982, de 5 de mayo, de protección civil del derecho al honor, a la intimidad personal y familiar y a la propia imagen, coord. por José Ramón DE VERDA Y BEAMONTE, Thomson-Aranzadi, Navarra, 2007.

BARRIENTOS ZAMORANO, M., El resarcimiento por daño moral en España y Europa, Ratio Legis, Salamanca, 2007.

- «Del daño moral al daño extrapatrimonial: la superación del pretium doloris», Revista Chilena de Derecho, vol. 35, N. ${ }^{\circ}$ 1, Editorial Pontificia Universidad Católica de Chile, Santiago, 2008.

BREBBIA, R. H., El daño moral, Editorial Bibliográfica Argentina. Buenos Aires, 1950.

BUSTO LAGO, J. M., La antijuridicidad del daño resarcible en la responsabilidad civil extracontractual, Tecnos, Madrid, 1998.

CAMMAROTA, A., Responsabilidad extracontractual. Hechos y actos ilícitos, T. I, Editorial De Palma, Buenos Aires, 1947.

CARBONNIER, J., Derecho Civil. Estudio Introductorio («Droit civil»), T. II, Vol. III, trad. de la primera edición francesa con adiciones de 
conversión al español por ZORRILLA RUIZ, M. M., Bosch, Barcelona, 1971.

CASADO ANDRÉS, B., «El concepto del daño moral bajo el prisma de la jurisprudencia», Revista Internacional de Doctrina y Jurisprudencia, Volumen 9, Universidad de Almería, Almería, 2015. Puede acceder a través de www.ual.es.

DALMARTELLO, A., "Danni morali contrattuali», $R D C$, anno XXV, Societá Editrice Libraria, Milano, 1933.

DE ÁNGEL YÁGUEZ, R., Tratado de Responsabilidad Civil, Cívitas, Madrid, 1993.

DE CUPIS, A., Il danno. Teoria generale della responsabilitá civile, Dott. A. Giuffré - Editore, Milano, 1946.

DEMOGUE, R., Traité des obligations en gènèral. Sources del obligaciones, T. IV, Librairie Arthur Rousseau, Paris, 1924.

DÍEZ-PICAZO Y PONCE DE LEÓN, L., Derecho de daños, Civitas, Madrid, 2000.

- El escándalo del daño moral, Thomson-Cívitas, Pamplona, 2008.

DÍEZ-PICAZO, L. y GULLÓN BALLESTEROS, A., Sistema de derecho civil, vol. II, 9. ${ }^{\text {e }}$ edic., Tecnos, Madrid, 2002.

DOMíNGUEZ HIDALGO, C. A., El daño moral, T. I, Editorial Jurídica de Chile, Santiago, 2000.

EUROPEAN GROUP ON TORT LAW, «Principios del derecho europeo de la responsabilidad civil», Viena, 2005, www.egtl.org.

FERRER VICENTE, J. M., "La cuestión de los daños morales», Difusión Jurídica y Temas de Actualidad (cuadernos prácticos), Madrid, 2007.

GARCÍA LÓPEZ, R., Responsabilidad civil por daño moral. Doctrina y Jurisprudencia, José M. ${ }^{a}$ Bosh Editor, S.A., Barcelona, 1990.

GARCÍA SERRANO, F. A., «El daño moral en la jurisprudencia civil», $A D C, 1972$.

GÓMEZ POMAR, F., «El sudor de la frente y el daño moral. Comentario a la STS, 1. a , 22.9.2004», InDret 1/2005, www.indret.com

— «Daño moral», InDret 1/2000, www.indret.com

JOSSERAND, L., Derecho civil, T. II, vol. I, revisado y completado por ANDRÉ BRUN, trad. de CUNCHILLOS Y MANTEROLA, S., Bosch y Cia, Buenos Aires, 1950. 
LALOU, H., Traité pratique de la responsabilicé civile, 5. ${ }^{a}$ edic., Librairie Dalloz, Paris, 1955.

LASARTE ÁlVAREZ, C., Principios de derecho civil. Parte general y derecho de la persona, T. I, 6. ${ }^{\text {a }}$ edic., Trivium, Madrid, 1998.

LLAMAS POMBO, E., Cumplimiento por equivalente y resarcimiento del daño al acreedor, Trivium, Madrid, 1999.

- La responsabilidad civil del médico. Aspectos tradicionales y modernos, Trivium, Madrid, 1988.

MACÍAS CASTILLO, A., El daño causado por el ruido y otras inmisiones, La Ley, Madrid, 2004.

MARTÍNEZ CALCERRADA Y GOMÉZ, L., «El daño moral: sus manifestaciones en derecho español», Diario La Ley, N. ${ }^{\circ}$ 6996-7001, Madrid, 2008.

MAZEAUD, H., MAZEAUD, L. y TUNC, A., Tratado teórico y práctico de la responsabilidad civil delictual y contractual, T. 1, Vol. I, trad. de la 5. ${ }^{\text {a }}$ edic. por ALCALÁ ZAMORA Y CASTILLO, L., Ediciones Jurídicas Europa-América, Buenos Aires, 1961.

MESSINEO, F., Derecho civil y comercial, traducción de SANTIAGO SENTÍS MELENDO, T. VI (relaciones obligatorias singulares), Ediciones Jurídicas Europa-América, Buenos Aires, 1955.

MINOZZI, A., Studio sul danno non patrimoniale (danno morale), 2. ${ }^{\mathrm{a}}$ edic., Societá Edetrice Libraira, Milano, 1909.

PASCUAL ESTEVILL, L., Derecho de daños, 2. ${ }^{a}$ edic., T. II, Bosch, Barcelona, 1955.

PÉREZ ONTIVEROS BAQUERO, C., Daño moral por incumplimiento de contrato, Thomson-Aranzadi, Navarra, 2006.

ROCA Y TRÍAS, E., Derecho de daños. Textos y materiales, 5. ${ }^{a}$ edic., Tirant lo Blanch, Valencia, 2007.

RODRÍGUEZ GUITIÁN, A. M., El derecho al honor de las personas jurídicas, Montecorvo, Madrid, 1996.

RODRÍGUEZ MARÍN, C., «Introducción al Derecho de Daños (II)», en Manual de valoración del daño corporal. Guía de aplicación del sistema de baremación para accidentes de circulación, coord. Javier LÓPEZ Y GARCÍA DE LA SERRANA, Thomson-Aranzadi, Navarra, 2007. 
ROVIRA SUIERO, M. E., La Responsabilidad Civil derivada de los Danos Ocasionados al Derecho al Honor, a la Intimidad Personal y Familiar y a la Propia Imagen, Cedecs, Barcelona, 1999.

SALAZAR VALLEJO, C. y GONZÁLEZ PUYANA, M. P., El daño moral, Pontificia Universidad Javeriana, Facultad de Ciencias Jurídicas y Socioeconómicas, Bogotá, 1990.

SANTOS BRIZ, J., La responsabilidad civil. Derecho sustantivo y derecho procesal, Montecorvo, Madrid, 1970.

SALVADOR CODERCH, P., El mercado de las ideas, Centro de Estudios Constitucionales, Madrid, 1990.

SCOGNAMIGLIO, R., "Il danno morale», Rivista di diritto civile, anno III, Parte Prima, Padova, Cedam, Casa Editrice dott. Antonio Milani, 1957.

VICENTE DOMINGO, E., Los daños corporales: tipología y valoración, José M. ${ }^{a}$ Bosh Editor, S. A., Barcelona, 1994.

- "El daño», en Tratado de responsabilidad civil, coordinado por Luis Fernando Reglero Campos, V. I, 3. ${ }^{a}$ edic., Thomson-Aranzadi, Navarra, 2006.

YZQUIERDO TOLSADA, M., Sistema de responsabilidad civil, contractual y extracontractual, Dykinson, Madrid, 2001.

ZANNONI, E. A., El daño en la responsabilidad civil, Astrea, 2. ${ }^{\text {e edic., }}$ Buenos Aires, 1987. 